\title{
SISTEMAS DE ADUBAÇÃO E CONSÓRCIO DE CULTURAS INTERCALARES E SEUS EFEITOS NAS VARIÁVEIS DE COLHEITA DA CULTURA DO MILHO ${ }^{1}$
}

\author{
JORGE W. CORTEZ ${ }^{2}$, CARLOS E. A. FURLANI ${ }^{3}$, ROUVERSON P. DA SILVA ${ }^{4}$
}

\begin{abstract}
RESUMO: A colheita é a operação final de campo do processo produtivo, e por isso os fatores que interferem na mesma devem ser observados e avaliados atentamente para reduzir ao mínimo as perdas nessa etapa. O objetivo deste trabalho foi avaliar a influência dos sistemas de adubação (em pré-semeadura e na semeadura) e dos consórcios de culturas intercalares (milho+mucuna-cinza-anã, milho+guandu-anão e milho+lablab) nas variáveis de colheita da cultura do milho em sistema plantio direto. O experimento foi realizado na UNESP de Jaboticabal - SP, no período de safra normal, utilizando-se do delineamento em blocos ao acaso, no esquema fatorial $(2 \times 3)$, com quatro repetições. Os componentes avaliados na colheita foram: diâmetro do colmo, altura de inserção da primeira espiga, altura da planta, número de espigas por planta, índice de espiga, número de fileiras na espiga, biomassa seca da palhada no solo, estande final, produtividade de grãos, fluxos de grãos, de palha e de sabugo e perdas na colheita. Os resultados demonstraram que o diâmetro do colmo, a altura de inserção da primeira espiga e a altura de plantas apresentaram maiores valores para o sistema de adubação na semeadura. O número de fileiras, espigas viáveis, índice de espiga, estande final, biomassa seca da palhada, produtividade, fluxos de palha, de sabugo, de grãos e as perdas na colheita não foram afetados pelos sistemas de adubação e os consórcios.
\end{abstract}

PALAVRAS-CHAVE: fluxo de material, perdas na colheita, mecanização agrícola.

\section{FERTILIZATION SYSTEM AND INTERCALATING CROPS CONSORTIUM AND THEIR EFFECTS ON VARIABLES OF CORN CROP HARVEST}

\begin{abstract}
The harvest is the final field operation of the productive process and, for this reason, the factors that interfere in it must be observed and attentively evaluated to reduce the losses to the minimum at this phase. The aim of this study was to evaluate the influence of fertilization systems (anticipated and in the sowing) and of the intercalating crops consortiums (Corn+Stizolobium deeringianum, Corn+Cajanus cajan and Corn+Dolichos lablab) at the variables of corn crop harvest under system of direct planting. The experiment was done at UNESP, Jaboticabal - SP, Brazil, during the regular crop time, designed in randomized blocks with four repetitions in a $2 \times 3$ factorial scheme. The components evaluated at harvest were: stem diameter, first spike insertion height, plant height, the number of spikes in the plant, spike rate, number of rows in the spike, dry biomass on soil, final stand, grain productiveness, grain and straw flow and the losses during harvest. The results demonstrated that the stem diameter, the first spike insertion height and the plant height presented higher values for the fertilization system at sowing. The number of rows, viable spikes, spike rate, final stand, dry biomass on soil, productiveness, straw and cob flow, grain flow and losses during harvest were not affected by the treatments.
\end{abstract}

KEYWORDS: material flow, losses during harvest, agricultural mechanization.

\footnotetext{
${ }^{1}$ Extraído da Tese de Doutorado do primeiro autor.

${ }^{2}$ Engo Agrônomo, Docente da Universidade Federal do Vale do São Francisco - UNIVASF, Colegiado de Engenharia Agrícola e Ambiental, Av. Antonio Carlos Magalhães, 510, Country Club, Juazeiro - BA, jorge.cortez@univasf.edu.br

${ }^{3}$ Eng ${ }^{\circ}$ Agrônomo, Prof. Adjunto, UNESP, Departamento de Engenharia Rural, Jaboticabal - SP, furlani@ fcav.unesp.br

${ }^{4}$ Eng ${ }^{0}$ Agrícola, Prof. Doutor, UNESP, Departamento de Engenharia Rural, Jaboticabal - SP, rouverson@ fcav.unesp.br

Recebido pelo Conselho Editorial em: 19-9-2008
}

Aprovado pelo Conselho Editorial em: 16-5-2009 


\section{INTRODUÇÃO}

A colheita mecanizada de milho é a última operação no ciclo da cultura que se destaca em razão das dificuldades e dos altos custos envolvidos (SOUZA et al., 2001). Desse modo, PORTELLA (1997) enfatiza que, para reduzir as perdas, é necessário o desenvolvimento de metodologias para regulagem de colhedoras, assim como o uso de novos mecanismos que potencializem o desempenho da máquina.

Para a colheita mecanizada do milho no sistema plantio direto, com o uso de culturas intercalares, esse sistema torna-se possível pelo milho apresentar maior espaçamento de cultivo, 0,75 a 1,00 m entre fileiras (MEROTTO JÚNIOR et al., 1997), e possuir altura de inserção da espiga acima de 1,0 m (MARCHÃO et al., 2005), o que possibilita a colheita sem maiores danos às culturas intercalares. Além disto, as culturas intercalares (leguminosas) acrescentam ao solo N via fixação biológica, que pode beneficiar a cultura do milho (COSTA \& SILVA, 2008) e proporciona palhada para a proteção do solo (CALEGARI et al., 1993).

Dados da pesquisa demonstram que a utilização do guandu-anão como cultura intercalar ao milho apresenta a menor produção de biomassa seca, principalmente devido ao baixo desenvolvimento inicial, sendo, então, recomendada para sistemas com consórcios (PELA, 2002).

Outra cultura recomendada para a adubação verde, principalmente em olericultura e no cultivo de frutíferas perenes e cafeeiros, é a mucuna-cinza-anã, que atinge altura máxima ao redor de $44-50 \mathrm{~cm}$, sendo também recomendada para consórcios de verão (GUIRRA, 2006). Dentre outras culturas, o lablab, que é uma herbácea perene e cultivada como anual (SENO et al., 1996), é um ótimo adubo verde e apresenta boa produção de forragem no outono (LOVADINI et al., 1972), produzindo cerca de $7.340 \mathrm{~kg} \mathrm{ha}^{-1}$ (ARF et al., 2000).

No momento da semeadura, além da decisão de implantação de culturas intercalares, o agricultor deve optar também pela forma de aplicação do adubo. O método de aplicação em sulcos é o mais utilizado, no entanto existem aqueles que fazem a distribuição do fertilizante na superfície do solo a lanço e em mistura com as sementes da cultura principal (SILVA \& BARBOSA FILHO, 2000), que pode acarretar danos à germinação. Os autores citam que, para a cultura do milho, a adubação realizada a $10 \mathrm{~cm}$ de profundidade propicia maior estande de plantas, quantidade de espigas e produtividade, em comparação com a adubação superficial. A produtividade do milho diferiu de acordo com a velocidade de operação da semeadura e com a profundidade de adubação, sendo que a adubação profunda proporcionou maior produtividade que a superficial (SILVA \& SILVEIRA, 2002).

No sistema plantio direto, a aplicação de fósforo pode ser realizada em superfície, devido que as plantas de cobertura podem influenciar no aproveitamento de fósforo, aumentando a disponibilidade; assim, parte do adubo pode ser aplicada em pré-semeadura (RODRIGUES, 2006).

Uma preocupação é que a adubação superficial fosfatada no plantio direto representa baixa eficiência agronômica, pois o fósforo deveria ser uniformemente incorporado na camada arável para que maior volume de raízes tivesse contato com o fertilizante (LOPES et al., 2003). No entanto, os autores verificaram, por resultados experimentais com fósforo marcado (32P), obtidos já na década de 1960 com a cultura do milho, nos Estados Unidos, que o 32P fertilizante, aplicado na superfície do solo no plantio direto, é absorvido pelas plantas nos períodos iniciais de seu desenvolvimento, em quantidade superior àquela observada quando incorporado ao solo no sistema convencional (no sulco, no momento da semeadura). Isso ocorre porque aumenta a proporção de solo fertilizado com fósforo e absorção, devido ao volume de raízes que entra em contato com o fertilizante.

O potássio, importante na fase inicial das culturas, tem sua máxima absorção no estádio vegetativo de 30 a 40 dias de desenvolvimento, com taxa superior à do nitrogênio e do fósforo, o que sugere maior necessidade de potássio na fase inicial, como elemento de arranque (COELHO et al., 2002). Segundo os autores, em anos com ocorrência de déficit hídrico após a semeadura, a aplicação de alta dose de potássio no sulco pode prejudicar a germinação das sementes pelo efeito salino, indicando, assim, a aplicação em pré-semeadura. 
Com a antecipação da adubação de semeadura na soja (P-K) em plantio direto, observou-se que ocorreu maior produção de biomassa da planta de cobertura e que não houve alteração na produção de grãos da cultura principal (SEGUATELLI, 2004).

As perdas na colheita mecanizada do milho variaram de $24 \mathrm{~kg} \mathrm{ha}^{-1}$ a $120 \mathrm{~kg} \mathrm{ha}^{-1}$, comparando a eficiência de colhedoras de 0 a 5 anos de uso (SILVA et al., 2004). GROTTA et al. (2007) avaliaram as perdas durante a colheita de milho e verificaram que ficaram próximas de $20 \mathrm{~kg} \mathrm{ha}^{-1}$.

Dados demonstram que a produtividade do milho consorciado com o feijão diminui em torno de 7,5\% (milho) quando a semeadura do feijão ocorre 15 dias antes, na mesma época, e 15 dias depois da semeadura do milho, sendo que esses dados não diferiram estatisticamente (FLESCH, 2002). Em vez de ser prejudicado, o milho foi favorecido com a presença do feijão, no caso das características de massa de espiga, massa de sabugo, massa de 100 grãos e produtividade (MACIEL et al., 2004). Uma vez que ocorra aumento na massa de espiga, sabugo e grãos, o fluxo de material dentro da colhedora irá aumentar, podendo ocasionar a fadiga do sistema com possíveis embuchamentos, quando a velocidade de deslocamento da colhedora não for adequada.

Diante do exposto, pressupõe-se que o uso das culturas intercalares, bem como a aplicação de adubo em pré-semeadura não afetam as variáveis na colheita do milho.

Assim, o objetivo do presente trabalho foi avaliar a interferência de sistemas de adubação (pré-semeadura e na semeadura) e do consórcio de culturas intercalares (mucuna-cinza-anã, guandu-anão e lablab) com a cultura do milho nas variáveis que determinam a eficiência de trilha e na produção de grãos.

\section{MATERIAL E MÉTODOS}

O experimento foi conduzido em área experimental da UNESP, Jaboticabal - SP, localizada nas coordenadas geodésicas: latitude $21^{\circ} 14^{\prime} \mathrm{S}$ e longitude $48^{\circ} 16^{\prime} \mathrm{W}$, com altitude média de $559 \mathrm{~m}$, declividade média de 4\%, em área de aproximadamente 1,5 ha. O clima, de acordo com a classificação de Köeppen, é Aw, subtropical úmido, com estiagem no período do inverno. Os dados de precipitação e temperatura média em que foi conduzida a cultura do milho sob os tratamentos de sistemas de adubação e consórcios conduzidos sem irrigação são apresentados na Figura 1.

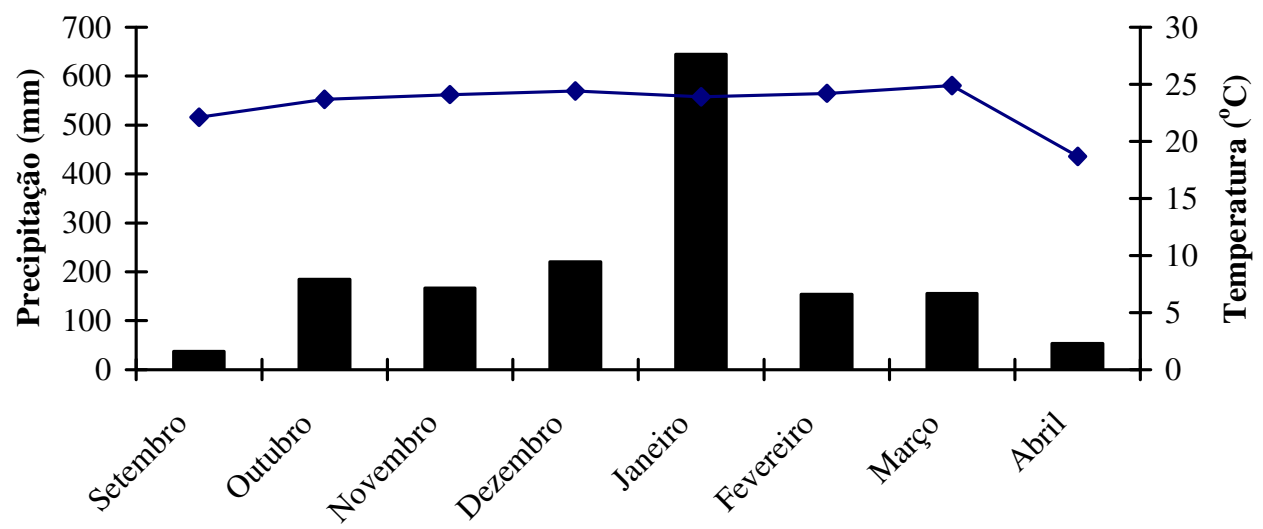

Meses 2006/2007

$\square$ Precipitação $(\mathrm{mm}) \multimap$ Temperatura

FIGURA 1. Dados meteorológicos mensais (precipitação pluviométrica e temperatura) nos anos de 2006/2007, obtidos do Departamento de Ciências Exatas da FCAV-UNESP, Jaboticabal. Monthly meteorological data (pluviometrical precipitation and temperature) in 2006/2007 obtained from the Exact Science Department of FCAV-UNESP, Jaboticabal. 
O solo da área experimental é o Latossolo Vermelho eutroférrico típico, A moderado, textura argilosa e relevo suave ondulado, conforme EMBRAPA (1999). Com a amostragem de solo e posterior análise química, obtiveram-se os resultados apresentados na Tabela 1, que serviram para a recomendação de adubação de semeadura e cobertura (RAIJ et al., 1985).

TABELA 1. Análise granulométrica e química do solo da área experimental. Granulometric and chemical soil analysis for experimental area.

\begin{tabular}{|c|c|c|c|c|c|c|c|c|c|c|c|c|c|}
\hline Prof. & Text & ira $(\mathrm{g}$ & $\left.\mathrm{kg}^{-1}\right)$ & $\mathrm{pH}$ & M.O. & P resina & $\mathrm{K}$ & $\mathrm{Ca}$ & $\mathrm{Mg}$ & $\mathrm{H}+\mathrm{Al}$ & SB & $\mathrm{T}$ & V \\
\hline$(\mathrm{cm})$ & Arg. & Sil. & Areia & $\mathrm{CaCl}_{2}$ & $\%$ & $\mathrm{mg} \mathrm{dm}^{-3}$ & -- & $\cdots$ & $--\mathrm{ml}$ & $\mathrm{ol}_{\mathrm{c}} \mathrm{dm}^{-3}$ & ------' & - & $\%$ \\
\hline$\overline{0-10}$ & 550 & 250 & 200 & 6,0 & 28 & 46 & 4,8 & 50 & 30 & 20 & 84,8 & 104,8 & 81 \\
\hline $10-20$ & & & & 5,7 & 23 & 37 & 4,5 & 38 & 17 & 25 & 59,5 & 84,5 & 70 \\
\hline
\end{tabular}

Arg.: argila; Sil.: silte; M.O.: matéria orgânica; SB: soma de bases; V: saturação por bases do solo; T: capacidade de troca de cátions a $\mathrm{pH} 7,0$.

A área experimental permaneceu em repouso nos anos de 1999 e 2000, porém com grande infestação de plantas daninhas, como capim-colonião (Panicum maximum Jacq.) e grama-seda (Cynodon dactylon (L.) Pers). Na área, foi realizado o manejo das plantas daninhas com roçadora e, posteriormente, o preparo convencional do solo com gradagem pesada e duas gradagens leves ao final de 2000. Em seguida, foi semeada a cultura do milheto para a implantação do sistema de plantio direto, cuja cultura principal foi a soja, na safra 2001/2002; a partir desse ano, ocorreu sucessão de culturas no verão, com milho e soja, e no inverno, a rotação de culturas com mucuna-cinza, crotalária, triticale, aveia e sorgo. Na safra 2006/2007, foi implantado o milho e os consórcios no início de dezembro de 2006, objeto de estudo deste trabalho.

Utilizou-se o delineamento em blocos ao acaso, no esquema fatorial $2 \times 3$, com quatro repetições, sendo dois sistemas de aplicação do adubo (pré-semeadura e na semeadura) e três consórcios (milho+mucuna-cinza-anã, milho+guandu-anão e milho+lablab). Cada parcela experimental ocupou área de $300 \mathrm{~m}^{2}(25 \times 12 \mathrm{~m})$ e, entre parcelas, no sentido longitudinal, foi reservado espaço de $15 \mathrm{~m}$ destinado à realização de manobras, tráfego de máquinas e estabilização dos conjuntos.

A aplicação do adubo em pré-semeadura foi realizada com o conjunto trator-semeadora, nas parcelas sorteadas com esse tratamento, com velocidade de 4,2 $\mathrm{km} \mathrm{h}^{-1}, 30$ dias antes da deposição das sementes, utilizando as sete linhas da semeadora espaçadas de $45 \mathrm{~cm}$; na semeadura, esse tratamento recebeu apenas as sementes, sendo o mecanismo de adubo (haste sulcadora) retirado da semeadora, assim a velocidade do conjunto trator-semeadora-adubadora foi de $6,6 \mathrm{~km} \mathrm{~h}^{-1}$. A aplicação de adubo na semeadura utilizou a semeadora com todos os mecanismos de contato com o solo, disco de corte, haste sulcadora para adubo, disco duplo para a semente e rodas compactadoras, na velocidade de $4,7 \mathrm{~km} \mathrm{~h}^{-1}$, sendo o adubo distribuído apenas na fileira do milho $(90 \mathrm{~cm})$.

A formação dos consórcios (milho+mucuna-cinza-anã, milho+guandu-anão e milho+lablab) foi obtida no momento da semeadura, em que as sementes das mesmas (leguminosas) foram depositadas a $7 \mathrm{~cm}$ de profundidade (90 $\mathrm{cm}$ de espaçamento), com o auxílio da roda de controle de profundidade da semeadora, enquanto o milho a $3 \mathrm{~cm}$ de profundidade, com espaçamento de $90 \mathrm{~cm}$, para obter atraso na emergência dos consórcios e melhor desenvolvimento do milho. Na semeadura, os depósitos de sementes das linhas da semeadora foram alternadamente preenchidos com milho e os consórcios.

Foram utilizados os equipamentos agrícolas: trator Valtra BM100 TDA, com potência de 73,6 kW, massa de $5.400 \mathrm{~kg}$; semeadora-adubadora marca Marchesan, modelo COP Suprema, com sete linhas para semeadura, espaçadas de $0,45 \mathrm{~m}$, com haste sulcadora com ângulo de ataque de $20^{\circ}$, disco de corte de $45,7 \mathrm{~cm}$, disco duplo de 40,6 cm, massa de $3.070 \mathrm{~kg}$; trator Ford 5610 , com potência de $52,9 \mathrm{~kW}$, com $200 \mathrm{~kg}$ de lastro dianteiro, velocidade de operação na pulverização de $6,5 \mathrm{~km} \mathrm{~h}^{-1}$ e na operação de adubação de cobertura a $5,0 \mathrm{~km} \mathrm{~h}^{-1}$; cultivador-adubador marca Jumil, com dois reservatórios de $50 \mathrm{~kg}$, que distribuem em quatro fileiras, acoplado ao sistema hidráulico 
de três pontos, sendo o acionamento pela tomada de potência do trator a $540 \mathrm{rpm}$; pulverizador Jacto, modelo Condor M12/75, com tanque de $600 \mathrm{~L}$, massa de $255 \mathrm{~kg}$, 24 bicos tipo leque (XR Teejet - 110.02VS para herbicida e 110.04 para inseticida), largura útil de $12 \mathrm{~m}$, e colhedora John Deere, modelo SLC 1165, com potência de $103 \mathrm{~kW}(140 \mathrm{cv})$, com plataforma para milho de 3,6 m de comprimento e rotação de $600 \mathrm{rpm}$ no cilindro.

Os insumos utilizados para eliminar plantas daninhas foram: herbicida agrícola Glifosato $480 \mathrm{~g} \mathrm{~L}^{-1}$, com dose de $5 \mathrm{~L} \mathrm{ha}^{-1}$ na calda de $120 \mathrm{~L} \mathrm{ha}^{-1}$, e segunda aplicação de 2,4 dichlorophenoxy $806 \mathrm{~g} \mathrm{~L}^{-1}$, na dose de $1,5 \mathrm{~L} \mathrm{ha}^{-1}$, antes da semeadura.

As sementes de milho (Zea mays L.) foram do híbrido simples DKB 390 (5,8 sementes por metro), com pureza e germinação de $96 \%$, com 60 mil plantas por hectare, maturação próxima a 120 dias (ciclo precoce) e altura de planta e de inserção da primeira espiga de 2,20 a 2,40 m e 1,25 a $1,40 \mathrm{~m}$, respectivamente, e somatória térmica até o florescimento de 845 graus-dia, apresentando folhas semieretas e Stay Green bom.

Para controle da lagarta-do-cartucho (Spodoptera frugiperda), utilizou-se de Cypermethrin, na dose de $150 \mathrm{~mL} \mathrm{ha}^{-1}$, e Lefenuron, na dose de $300 \mathrm{~mL} \mathrm{ha}^{-1}$, com calda de $300 \mathrm{~L} \mathrm{ha}^{-1}$.

Os consórcios foram formados com sementes de guandu-anão (Cajanus cajan), sendo distribuídas 12 sementes por metro; sementes de mucuna-cinza-anã (Stizolobium deeringianum Bort.), sendo distribuídas nove sementes por metro; sementes de lablab (Dolichos lab lab), sendo distribuídas nove sementes por metro.

Para a adubação, utilizou-se de adubo com a fórmula 8-28-16 (N-P-K), na dose de $370 \mathrm{~kg} \mathrm{ha}^{-1}$, tanto na adubação de pré-semeadura (30 dias antes da semeadura) como na semeadura, e adubação de cobertura com ureia, na dose de $140 \mathrm{~kg} \mathrm{ha}^{-1}$, aos 14 dias após a semeadura (quatro folhas), e mais $200 \mathrm{~kg} \mathrm{ha}^{-1}$ aos 30 dias após a semeadura (sete folhas).

A determinação do diâmetro do colmo, altura de inserção da primeira espiga (AIPE) e altura de plantas foi efetuada em cinco plantas de milho de cada parcela, tomando como base a região do colo da planta ( $\pm 5 \mathrm{~cm}$ de altura), ponto de inserção da primeira espiga no colmo e a folha-bandeira (ponto inserção no colmo), respectivamente. Utilizou-se, para medir o diâmetro do colmo, de paquímetro digital com precisão de $0,1 \mathrm{~mm}$; para a altura de plantas e AIPE, utilizou-se de trena com precisão de $0,5 \mathrm{~cm}$; essas medidas foram realizadas aos 90 dias após a semeadura.

A biomassa da palhada (plantas daninhas, culturas intercalares e palha sobre o solo) sobre o solo (antes da colheita) foi determinada com o auxílio de armação de $0,25 \mathrm{~m}^{2}$, posicionada na entrefileira, na parte central da parcela, aos 120 dias após a semeadura do milho. Em seguida, as amostras da massa vegetal foram pesadas e colocadas em estufa com circulação forçada de ar, por 48 h e a $75^{\circ} \mathrm{C}$.

O número de espigas viáveis por planta (apresentam produção de grãos), índice de espiga (número de espigas por planta) e o estande final foram calculados com base nos valores obtidos das plantas de milho em $2 \mathrm{~m}$, de duas fileiras, na parte central da parcela. Com a coleta de dez espigas na parte central da parcela, foram tomadas as medidas do número de fileiras de grãos na espiga, número de grãos em uma fileira e produtividade. Com as mesmas 10 espigas, foram calculados o fluxo de material colhido em grãos, sabugo e palha, obtidos por meio da eq.(1). A massa de grãos foi obtida após a trilha das espigas em máquina estacionária específica para o milho.

$$
\varphi_{\mathrm{x}}=\frac{\mathrm{Lp} \mathrm{v} \mathrm{M}_{\mathrm{x}}}{10000}
$$

em que,

$\varphi_{\mathrm{x}}$ - fluxo total de alimentação de grãos, ou de sabugo, ou de palha, $\mathrm{kg} \mathrm{s}^{-1}$;

Lp - largura da plataforma de corte da colhedora, $\mathrm{m}$;

$\mathrm{v}$ - velocidade de deslocamento da colhedora, $3,6 \mathrm{~m} \mathrm{~s}^{-1}$, e

$\mathrm{M}_{\mathrm{x}}$ - massa seca de grãos, ou de sabugo, ou de palha, $\mathrm{kg}$. 
As perdas na colheita foram coletadas tendo como referência a metodologia desenvolvida por MESQUITA et al. (2001), que recomendam armação retangular de $1 \mathrm{~m}^{2}$ posicionada transversalmente ao deslocamento da colhedora, sendo coletada uma amostra por parcela. As perdas de grãos de milho foram corrigidas para $13 \%$ de umidade.

Os dados foram submetidos à análise de variância e, quando o valor do teste $\mathrm{F}$ foi significativo a pelo menos $5 \%$ de probabilidade, realizou-se o teste de Tukey, a 5\% de probabilidade para a comparação de médias (BANZATTO \& KRONKA, 2006).

\section{RESULTADOS E DISCUSSÃO}

A adubação na semeadura resultou em maiores diâmetro de colmo, AIPE e altura de plantas $(\mathrm{P} \leq 0,05)$, enquanto os consórcios não influenciaram nesses parâmetros $(\mathrm{P}>0,05)$ e não houve interação significativa entre adubação e consórcios $(\mathrm{P}>0,05)$ para essas variáveis (Tabela 2).

$\mathrm{O}$ menor diâmetro dos colmos de milho encontrado na adubação de pré-semeadura $(\mathrm{P} \leq 0,05)$ pode ser indicativo de que a mesma não seja opção para híbridos que apresentem problemas de acamamento (Tabela 2), uma vez que o adubo deve ter sido aproveitado pelo consórcio (leguminosa) e como resultou em menor quantidade para o milho, esse apresentou menor diâmetro. A adubação na semeadura do milho resultou em diâmetro médio do colmo 8,6\% maior do que a adubação de pré-semeadura. Normalmente, o diâmetro do colmo apresenta correlação com a produtividade por se tratar de um órgão de reserva da planta (CRUZ et al., 2008), justificando que a adubação de semeadura é mais vantajosa pelo maior diâmetro proporcionado. $\mathrm{O}$ colmo atua como estrutura de armazenamento de sólidos solúveis que serão utilizados, posteriormente, na formação dos grãos (FANCELLI \& DOURADO-NETO, 2000).

A adubação de pré-semeadura não proporcionou as mesmas condições de desenvolvimento para a planta de milho do que a adubação na semeadura, o que pode ser constatado pela variável AIPE e altura de plantas (Tabela 2). No tratamento com adubação na semeadura em relação à pré-semeadura, ocorre diferença de 5\% para a AIPE. Quanto maior a AIPE, maior poderá ser a altura da plataforma da colhedora. Isso pode evitar embuchamentos e danos às plantas consorciadas com o milho. Na adubação em pré-semeadura em sulcos espaçados de $45 \mathrm{~cm}, 30$ dias antes da semeadura, o adubo ficou prontamente disponível para as plantas (milho e leguminosas); dessa forma, supõe-se que o consórcio tenha aproveitado o adubo, diminuindo a disponibilidade para o milho, influenciando nas alturas da espiga e da planta.

A altura média das plantas de milho (Tabela 2) foi modificada pelo sistema de adubação e a adubação na semeadura produziu plantas com altura 7,8\% maior do que as da adubação de présemeadura. Como a altura de plantas se relaciona de maneira direta com o AIPE, ambas apresentaram comportamento semelhante. Dentre os componentes morfológicos, a altura de plantas não tem, geralmente, correlação com a produtividade; cultivares modernas, com alto potencial produtivo, são, em sua maioria, de porte baixo, mas também se podem encontrar materiais de porte alto com desempenhos semelhantes aos baixos (CRUZ et al., 2008). SKORA NETO (2003) verificou que a altura de plantas é a medida mais fácil para avaliar a competição para as plantas de milho; desse modo, os consórcios não afetaram o desenvolvimento das plantas de milho neste experimento.

Dentre os parâmetros apresentados na Tabela 2, nota-se que o coeficiente de variação foi baixo, pois se encontra menor do que 10\% (PIMENTEL GOMES, 2000). Os baixos valores do C.V. podem ser explicados pelo fato de que as variáveis avaliadas são fortemente relacionadas com características genéticas. Isso foi descrito por ROSOLEM (1995), pois à medida que a planta se aproxima do estádio reprodutivo, se o ambiente for propício, a tendência é de todas as plantas se igualarem, pois a conformação final da planta é determinada geneticamente. 
TABELA 2. Síntese de análise de variância para componentes morfológicos da planta de milho: diâmetro do colmo, altura de inserção da primeira espiga (AIPE) e altura de plantas. Synthesis of variance analysis for morphological components of the corn plant: stem diameter, height of the first spike insertion (AIPE/HFSI) and height of plants.

\begin{tabular}{|c|c|c|c|}
\hline \multirow{2}{*}{ Fatores } & \multicolumn{3}{|c|}{ Variáveis } \\
\hline & Diâmetro do Colmo (mm) & AIPE $(\mathrm{cm})$ & Altura de Plantas $(\mathrm{cm})$ \\
\hline \multicolumn{4}{|l|}{ Adubação } \\
\hline Pré-semeadura & $18,6 \mathrm{~B}$ & $119,1 \mathrm{~B}$ & $211,3 \mathrm{~B}$ \\
\hline Na semeadura & $20,2 \mathrm{~A}$ & $125,2 \mathrm{~A}$ & $227,7 \mathrm{~A}$ \\
\hline \multicolumn{4}{|l|}{ Consórcios } \\
\hline Mucuna-cinza-anã & 20,0 & 119,6 & 217,6 \\
\hline Guandu-anão & 19,1 & 123,5 & 220,2 \\
\hline Lablab & 19,1 & 123,2 & 220,6 \\
\hline \multicolumn{4}{|l|}{ Teste F } \\
\hline Adubação (A) & $9,0^{* *}$ & $6,4 *$ & $35,2 * *$ \\
\hline Consórcios (C) & $1,1^{\mathrm{NS}}$ & $1,1^{\mathrm{NS}}$ & $0,5^{\mathrm{NS}}$ \\
\hline $\mathrm{A} \times \mathrm{C}$ & $0,2^{\mathrm{NS}}$ & $2,9^{\mathrm{NS}}$ & $0,6^{\mathrm{NS}}$ \\
\hline C.V. & 7,0 & 4,8 & 3,1 \\
\hline
\end{tabular}

O número de fileiras de grãos por espiga, de espigas viáveis, o índice de espiga e o estande final não foram afetados pelos tratamentos $(\mathrm{P}>0,05)$ e interações avaliadas (Tabela 3$)$, enquanto o número de grãos na fileira sofreu efeito da interação sistema de adubação $(\mathrm{P} \leq 0,05)$ e os consórcios (Tabela 4).

TABELA 3. Síntese de análise de variância para os componentes de produtividade da planta de milho: número de fileiras (NF), número de grãos na fileira (NGF), número de espigas viáveis (NEV), índice de espiga (IE) e estande final (EF). Variance analysis synthesis for components of productiveness of corn plant: number of row (NF), number of grains in the row (NGF), number of viable spikes (NEV), spike rate (IE) and final stand (EF).

\begin{tabular}{|c|c|c|c|c|c|}
\hline \multirow[b]{2}{*}{ Fatores } & \multicolumn{5}{|c|}{ Variáveis } \\
\hline & $\mathrm{NF}$ & NGF & $\mathrm{NEV}$ & $\mathrm{IE}$ & $\begin{array}{c}\text { EF } \\
\left(\text { plantas ha }^{-1}\right)\end{array}$ \\
\hline \multicolumn{6}{|l|}{$\overline{\text { Adubação }}$} \\
\hline Pré-semeadura & 15 & 32 & 11 & 1 & 59.722 \\
\hline Na semeadura & 15 & 32 & 11 & 1 & 61.574 \\
\hline \multicolumn{6}{|l|}{ Consórcios } \\
\hline Mucuna-cinza-anã & 15 & 30 & 11 & 1 & 59.375 \\
\hline Guandu-anão & 15 & 33 & 11 & 1 & 59.722 \\
\hline Lablab & 15 & 31 & 11 & 1 & 62.847 \\
\hline \multicolumn{6}{|l|}{ Teste F } \\
\hline Adubação (A) & $0,1^{\mathrm{ns}}$ & $0,1^{\mathrm{ns}}$ & $0,5^{\mathrm{ns}}$ & $0,1^{\mathrm{ns}}$ & $0,5^{\mathrm{ns}}$ \\
\hline Consórcios (C) & $0,5^{\mathrm{ns}}$ & $5,0 *$ & $0,7^{\mathrm{ns}}$ & $0,3^{\mathrm{ns}}$ & $0,7^{\mathrm{ns}}$ \\
\hline $\mathrm{A} \times \mathrm{C}$ & $0,2^{\mathrm{ns}}$ & $5,4 *$ & $2,3^{\mathrm{ns}}$ & $0,1^{\mathrm{ns}}$ & $0,5^{\mathrm{ns}}$ \\
\hline C.V. & 7,0 & 5,2 & 10,0 & 6,6 & 10,4 \\
\hline
\end{tabular}


TABELA 4. Síntese do desdobramento da interação adubação (A) e consórcios (C), para o número de grãos na fileira da espiga do milho. Deployment synthesis of the interaction of adubation (A) and consortiums (C) of the number of grains in the row of the corn spike.

\begin{tabular}{lcc}
\hline \multirow{2}{*}{ Consórcios } & \multicolumn{2}{c}{ Adubação } \\
\cline { 2 - 3 } & Pré-semeadura & Semeadura \\
\hline Mucuna-cinza-anã & $31,7 \mathrm{Aba}$ & $29,7 \mathrm{Ba}$ \\
Guandu-anão & $33,5 \mathrm{Aa}$ & $33,0 \mathrm{Aa}$ \\
Lablab & $29,7 \mathrm{Bb}$ & $33,0 \mathrm{Aa}$ \\
\hline
\end{tabular}

Médias seguidas de mesma letra maiúscula na coluna e minúscula na linha não diferem entre si, pelo teste de Tukey, a $5 \%$ de probabilidade.

O número de espigas viáveis e o índice de espiga (Tabela 3) são características intrínsecas do híbrido, definido pelo seu próprio potencial, e verifica-se que ocorreu uma espiga por planta (índice de espiga) e toda planta ter apenas uma espiga viável (número de espigas viáveis).

Pode-se observar que houve variação máxima de $6 \%$ no estande final da cultura do milho (Tabela 3), diferença essa não significativa $(P>0,05)$, evidenciando que os tratamentos não interferiram na consolidação do estande final para as plantas de milho.

No sistema de adubação na semeadura (Tabela 4), a cultura mucuna-cinza-anã difere em $10 \%$ do número de grãos na fileira do milho das culturas guandu-anão e lablab ( $\mathrm{P} \leq 0,05)$. No sistema de adubação em pré-semeadura, ocorre diferença de $11 \%(\mathrm{P} \leq 0,05)$ entre o guandu-anão e o lablab. Essa diferença ocorre, provavelmente, devido ao tipo de crescimento das culturas implantadas, pois o lablab é de crescimento inicial rápido, o que facilita a absorção do adubo, disponibilizando menos para o milho, o que resultou em menor número de grãos na espiga. Apesar dessa diferença, o número de fileiras e a produtividade não apresentam nenhuma relação segundo os dados de pesquisa (CASAGRANDE \& FORNASIERI FILHO, 2002).

Para as culturas, individualmente (Tabela 4), a mucuna-cinza-anã e o guandu-anão não diferiram nos sistemas de adubação $(\mathrm{P}>0,05)$, somente dentro do lablab ocorre diferença significativa $(\mathrm{P} \leq 0,05)$ entre adubação de pré-semeadura e na semeadura, na ordem de $10 \%$. Como na adubação de pré-semeadura o adubo foi mais bem distribuído na área (fileiras de $45 \mathrm{~cm}$ ), é provável que o lablab tenha aproveitado o adubo, diminuindo, assim, a disponibilidade para o milho, o que reduziu o número de grãos na fileira.

Não houve diferença de acumulação da biomassa seca (Tabela 5) sobre o solo por efeito dos sistemas de adubação e pelos de consórcios $(\mathrm{P}>0,05)$, o que pode ser explicado pelo alto valor do coeficiente de variação (PIMENTEL GOMES, 2000), devido à irregularidade da presença de plantas daninhas na área. Quanto ao fluxo de material dentro da colhedora (Tabela 5), não houve diferença para nenhuma das variáveis $(\mathrm{P}>0,05)$. Os valores de fluxo na colhedora de milho foram de $4,3 \mathrm{~kg} \mathrm{~s}^{-1}$, para o fluxo total, e de 3,3 $\mathrm{kg} \mathrm{s}^{-1}$, para o fluxo de grãos (GROTTA et al., 2007), próximo ao deste experimento.

Nenhum dos fatores aplicados diferenciou-se com relação à produtividade do milho $(\mathrm{P}>0,05)$; na soja, ESTEVES (2000) conclui que os teores dos nutrientes na planta e a produtividade foram maiores no sistema de adubação de pré-semeadura com fósforo e potássio.

As perdas na colheita de milho (Tabela 5) não apresentaram diferença significativa em nenhum dos fatores testados $(\mathrm{P}>0,05)$. Aliado a isso, pode-se considerar a influência do C.V., que foi alto (PIMENTEL GOMES, 2000). Os altos valores de coeficiente de variação podem estar associados à irregularidade das espigas e ao fluxo de material que entra na colhedora. TABILE et al. (2008) encontraram valores de coeficiente de variação nas perdas na colheita de milho de aproximadamente $60 \%$. 
TABELA 5. Síntese de análise de variância para biomassa da palhada (BP), fluxo de palha, fluxo de sabugo, fluxo de grãos, perdas e produtividade (P). Synthesis of variance analysis for dry biomass on soil (BP), straw flow, corncob flow, grain flow, losses and productiveness $(\mathbf{P})$.

\begin{tabular}{|c|c|c|c|c|c|c|}
\hline \multirow{2}{*}{ Fatores } & \multirow{2}{*}{$\begin{array}{c}\text { BP } \\
\left(\mathrm{kg} \mathrm{ha}^{-1}\right)\end{array}$} & \multicolumn{3}{|c|}{ Fluxo $\left(\mathrm{kg} \mathrm{s}^{-1}\right)$} & \multirow{2}{*}{$\begin{array}{l}\text { Perdas } \\
\left(\mathrm{kg} \mathrm{ha}^{-1}\right)\end{array}$} & \multirow{2}{*}{$\begin{array}{c}\mathrm{P} \\
\left(\mathrm{Mg} \mathrm{ha}^{-1}\right)\end{array}$} \\
\hline & & Palha & Sabugo & Grãos & & \\
\hline \multicolumn{7}{|l|}{ Adubação } \\
\hline Pré-semeadura & $3.417 \mathrm{~A}$ & $0,4 \mathrm{~A}$ & $0,6 \mathrm{~A}$ & $3,6 \mathrm{~A}$ & $26,4 \mathrm{~A}$ & $10,1 \mathrm{~A}$ \\
\hline Na semeadura & $2.500 \mathrm{~A}$ & $0,4 \mathrm{~A}$ & $0,6 \mathrm{~A}$ & $3,6 \mathrm{~A}$ & $25,9 \mathrm{~A}$ & $10,1 \mathrm{~A}$ \\
\hline \multicolumn{7}{|l|}{ Consórcios } \\
\hline Mucuna-cinza-anã & $3.450 \mathrm{~A}$ & $0,4 \mathrm{~A}$ & $0,6 \mathrm{~A}$ & $3,5 \mathrm{~A}$ & $16,4 \mathrm{~A}$ & $9,6 \mathrm{~A}$ \\
\hline Guandu-anão & $3.100 \mathrm{~A}$ & $0,4 \mathrm{~A}$ & $0,6 \mathrm{~A}$ & $3,8 \mathrm{~A}$ & $19,9 \mathrm{~A}$ & $10,4 \mathrm{~A}$ \\
\hline Lablab & $2.325 \mathrm{~A}$ & $0,4 \mathrm{~A}$ & $0,6 \mathrm{~A}$ & $3,7 \mathrm{~A}$ & $42,2 \mathrm{~A}$ & $10,3 \mathrm{~A}$ \\
\hline \multicolumn{7}{|l|}{ Teste F } \\
\hline Adubação (A) & $2,3^{\mathrm{ns}}$ & $1,9^{\mathrm{ns}}$ & $0,3^{\mathrm{ns}}$ & $0,1^{\mathrm{ns}}$ & $0,1^{\mathrm{NS}}$ & $0,1^{\mathrm{ns}}$ \\
\hline Consórcios (C) & $1,2^{\mathrm{ns}}$ & $1,2^{\mathrm{ns}}$ & $0,1^{\mathrm{ns}}$ & $0,9^{\mathrm{ns}}$ & $3,2^{\mathrm{NS}}$ & $0,9^{\mathrm{ns}}$ \\
\hline $\mathrm{A} \times \mathrm{C}$ & $0,7^{\mathrm{ns}}$ & $1,6^{\mathrm{ns}}$ & $1,5^{\mathrm{ns}}$ & $0,6^{\mathrm{ns}}$ & $0,5^{\mathrm{NS}}$ & $0,5^{\mathrm{ns}}$ \\
\hline C.V. & 50,2 & 14,4 & 12,4 & 12,8 & 83,9 & 13,0 \\
\hline
\end{tabular}

As perdas foram baixas (média de $26,2 \mathrm{~kg} \mathrm{ha}^{-1}$ ) se comparadas com o limite tolerável de $60 \mathrm{~kg} \mathrm{ha}^{-1}$, citado por MESQUITA et al. (2002). GROTTA et al. (2007) avaliaram as perdas durante a colheita de milho e verificaram que as mesmas ficaram próximas de $20 \mathrm{~kg} \mathrm{ha}^{-1}$. GRIFFIN (1991) cita que o nível aceitável de perda na colheita mecânica se encontra no intervalo de 3 a 5\%. Neste experimento, as perdas chegaram a $0,3 \%$, com produtividade média de $10,1 \mathrm{Mg} \mathrm{ha}^{-1}$.

\section{CONCLUSÕES}

A adubação de pré-semeadura proporcionou plantas de milho mais desenvolvidas, destacando-se a menor altura de inserção da espiga que favorece a colheita mecanizada, principalmente na presença de culturas intercalares.

Com exceção do número de fileiras de grãos por espiga, os demais parâmetros de produtividade, de trilha e de perdas não foram afetados pelos sistemas de adubação e pelos consórcios.

\section{REFERÊNCIAS}

ARF, O.; BUZETTI, S.; ALVES, M.C.; SÁ, M.E.; RODRIGUES, R.A.F.; HERNANDEZ, F.B.T. Efeito da época de semeadura da mucuna-preta (Stizolobium aterrimum) e lablab (Dolichos lablab) intercaladas na cultura do milho (Zea mays). Ciência e Agrotecnologia, Lavras, v.24, n.4, p.898904, 2000.

BANZATTO, D.A.; KRONKA, S.N. Experimentação agrícola. Jaboticabal: Funep, 2006. 237 p.

CALEGARI, A.; ALCÂNTARA, P. B.; MIYASAKA, S.; AMADO, T.J.C. Caracterização das principais espécies de adubo verde. In: COSTA, M.B.B. da (Coord.). Adubação verde no sul do Brasil. 2.ed. Rio de Janeiro: ASPTA, 1993. p.207-328.

CASAGRANDE, J.R.R.; FORNASIERI FILHO, D. Adubação nitrogenada na cultura do milho safrinha. Pesquisa Agropecuária Brasileira, Brasília, v.37, n.1, p.33-40, 2002.

COELHO, A.M.; FRANÇA, G.E.; PITTA, G.V.E.; ALVES, V.M.C.; HERNANI, L.C. Cultivo do milho: nutrição e adubação. Sete Lagoas: Embrapa, 2002. 12 p. (Comunicado Técnico, 44) 
COSTA, A.S.V.; SILVA, M.B. Sistemas de consórcio milho-feijão para a região do Vale do Rio Doce, Minas Gerais. Ciência e Agrotecnologia, Lavras, v.32, n.2, p.663-667, 2008.

CRUZ, S.C.S.; PEREIRA, F.R.S.; SANTOS JÚNIOR; ALBUQUERQUE, A.W.; PEREIRA, R.G. Adubação nitrogenada para o milho cultivado em sistema plantio direto, no Estado de Alagoas. Revista Brasileira Engenharia Agrícola e Ambiental, Campina Grande, v.12, n.1, p.62-68, 2008.

EMBRAPA. EMPRESA BRASILEIRA DE PESQUISA AGROPECUÁRIA. Sistema brasileiro de classificação de solos. Brasília, 1999. 412 p.

ESTEVES, J.A.F. Produção de soja em função da antecipação da adubação fosfatada e potássica em semeadura direta. 2000. 107 f. Dissertação (Mestrado em Agricultura) - Faculdade de Ciências Agronômicas, Universidade Estadual Paulista, Botucatu, 2000.

FANCELLI, A.L.; DOURADO-NETO, D. Milho: Ecofisiologia e rendimento. In: FANCELLI, A.L.; DOURADO NETO, D. (Coords.). Tecnologia da produção de milho. Piracicaba: ESALQ, USP, 1997. p.157-170.

FLESCH, R.D. Efeitos temporais e espaciais no consórcio intercalar de milho e feijão. Pesquisa Agropecuária Brasileira, Brasília, v.37, n.1, p.51-56, 2002.

GRIFFIN, G.A. Combine harvesting: operating maintaining and improving efficiency of combines. $4^{\text {th }}$ ed. Fundamentals of Machine Operation. Illinois: John Deere \& Company/Malone, 1991 . 207 p.

GROTTA, D.C.C.; FURLANI, C.E.A.; SILVA, R.P.; CORTEZ, J.W. Cultura do milho em diferentes profundidades de deposição de adubo sobre duas culturas de cobertura. Revista de Biologia e Ciências da Terra, Campina Grande, v.6, n.2, p.65-71, 2007.

GUIRRA. Mucuna-anã. Disponível em: <www.guirra.com.br>. Acesso em: 18 set. 2006.

LOPES, A.S.; WIETHOLTER, S.; GUILHERME, L.R.G.; SILVA, C.A. Sistema plantio direto: bases para o manejo da fertilidade do solo. São Paulo: ANDA, 2003. 115 p.

LOVADINI, L.A.C.; MASCARENHAS, H.A.A.; MIYASAKA, S.; PASTANA, F.I.; NERY, C.; LAUN, L.P.R. Emprego de Dolichos lablab como adubo verde. Estudo do plantio intercalado na cultura do milho. Bragantia, Campinas, v.5, p.97-108, 1972.

MACIEL, A.D.; ARF, O.; SILVA, M.G.; SÁ, M.E.; BUZETTI, S.; ANDRADE, J.A.C.; SOBRINHO, E.B. Comportamento do milho consorciado com feijão em sistema plantio direto. Acta Scientiarum Agronomy, Maringá, v.26, n.3, p.309-314, 2004.

MARCHÃO, R.L.; BRASIL, E.M.; DUARTE, J.B.; GUIMARÃES, C.M.; GOMES, J.A. Densidade de plantas e características agronômicas de híbridos de milho sob espaçamento reduzido entre linhas. Pesquisa Agropecuária Tropical, Goiânia, v.35, n.2, p.93-101, 2005.

MEROTTO JÚNIOR, A.; ALMEIDA, M.L.; FUCHS, O. Aumento no rendimento de grãos de milho através do aumento da população de plantas. Ciência Rural, Santa Maria, v.27, n.4, p.549$554,1997$.

MESQUITA. C.M.; COSTA, N.P.; PEREIRA, J.E.; MAURINA, A.C.; ANDRADE, J.G.M. Caracterização da colheita mecanizada da soja no Paraná. Engenharia Agrícola, Jaboticabal, v.21, n.2, p.197-205, 2001.

MESQUITA. C.M.; COSTA, N.P.; PEREIRA, J.E.; MAURINA, A.C.; ANDRADE, J.G.M. Perfil da colheita mecânica da soja no Brasil: safra 1998/1999. Engenharia Agrícola, Jaboticabal, v.22, n.3, p.398-406, 2002.

PELA, A. Uso de plantas de cobertura em pré-safra e seus efeitos nas propriedades físicas do solo e na cultura do milho em plantio direto na região de Jaboticabal - SP. 53 f. 2002. Dissertação (Mestrado em Produção Vegetal) - Faculdade de Ciências Agrárias e Veterinárias, Universidade Estadual Paulista, Jaboticabal, 2002. 
PIMENTEL GOMES, F. Curso de estatística experimental. Piracicaba: ESALQ, 2000. 477 p.

PORTELLA, J.A. Perdas de trigo, de soja e de milho x umidade do grão durante a colheita mecanizada. In: CONGRESSO BRASILEIRO DE ENGENHARIA AGRÍCOLA, 26., 1997, Campina Grande. Anais... Campina Grande: Associação Brasileira de Engenharia Agrícola, 1997. 1 CD-ROM.

RAIJ, B.V.; SILVA, N.M.; BATAGLIA, O.C.; GUAGGIO, J.A.; HIROGE, R.; CANTARELLA, H.; BELLINAZZI JÚNIOR, R.; DECHEN, A.R.; TRANI, P.E. Recomendações de adubação e calagem para o Estado de São Paulo. Campinas: IAC, 1985. 107 p.

RODRIGUES, C.R. Frações de fósforo e produção da soja e do feijoeiro em sucessão a gramíneas adubadas com diferentes fertilizantes fosfatados. 113 f. 2006. Tese (Doutorado em Solos e Nutrição de Plantas) - Universidade Federal de Lavras, Lavras - MG, 2006.

ROSOLEM, C.A. Relações solo-planta na cultura do milho. Jaboticabal: Funep, 1995. 53 p.

SEGUATELLI, C.R. Produtividade da soja em semeadura direta com antecipação da adubação fosfatada e potássica na cultura de Eleusine coracana (L.) Gaertn. 58 f. 2004. Dissertação

(Mestrado em Fitotecnia) - Escola Superior de Agricultura "Luiz de Queiroz", Universidade de São Paulo, Piracicaba, 2004.

SENO, M.S.; GOMES, L.; CORTELAZZO, A.L. Caracterização do material de reserva em feijão-guandu, lablab e mucuna. Bragantia, Campinas, v.55, n.1, p.67-73, 1996.

SILVA, J.G.; SILVEIRA, P.M. Avaliação de uma semeadora adubadora na cultura do milho. Santo Antônio de Goiás: Embrapa Arroz e Feijão, 2002. 19 p. (Boletim de Pesquisa e Desenvolvimento).

SILVA, O.F.; BARBOSA FILHO, M.P. Adubação de cobertura com ureia: a alternativa mais econômica para a cultura do feijoeiro irrigado em sistema plantio direto. Santo Antonio de Goiás: Embrapa, 2000. 2 p. (Pesquisa em Foco, 39)

SILVA, R.P.; CAMPOS, M.A.O.; MESQUITA, H.C.B.; ZABANI, S. Perdas na colheita mecanizada de milho no Triângulo Mineiro e Alto Paranaíba - MG. FAZU em Revista, Uberaba, n.1, p.3-10, 2004.

SKORA NETO, F. Uso de caracteres fenológicos do milho como indicadores do início da interferência causada por plantas daninhas. Planta Daninha, Viçosa, v.21, n.1, p.81-87, 2003.

SOUZA, C.M.A.; QUEIROZ, D.M.; CECON, P.R.; MANTOVANI, E.C. Avaliação de perdas em uma colhedora de fluxo axial para feijão. Revista Brasileira de Engenharia Agrícola e Ambiental, Campina Grande, v.5, n.3, p.530-537, 2001.

TABILE, R.A.; TOLEDO, A.; FURLANI, C.E.A.; SILVA, R.P.; GROTTA, D.C.C.; CORTEZ, J.W. Perdas na colheita de milho em função da rotação do cilindro trilhador e umidade dos grãos. Scientia Agrária, Curitiba, n.9, v.4, p.505-510, 2008. 